Article

\title{
Explosion Characteristics of Propanol Isomer-Air Mixtures
}

\author{
Jan Skřínský * (D) and Tadeáš Ochodek \\ Energy Research Center, VŠB-Technical University of Ostrava, 17. listopadu 2172/15, \\ 70800 Ostrava, Czech Republic; tadeas.ochodek@vsb.cz \\ * Correspondence: jan.skrinsky@vsb.cz; Tel.: +420-597-324-931
}

Received: 15 March 2019; Accepted: 21 April 2019; Published: 25 April 2019

check for

updates

\begin{abstract}
This paper describes a series of experiments performed to study the explosion characteristics of propanol isomer (1-propanol and 2-propanol)-air binary mixtures. The experiments were conducted in two different experimental arrangements-a $0.02 \mathrm{~m}^{3}$ oil-heated spherical vessel and a $1.00 \mathrm{~m}^{3}$ electro-heated spherical vessel-for different equivalence ratios between 0.3 and 1.7, and initial temperatures of 50,100 , and $150{ }^{\circ} \mathrm{C}$. More than 150 pressure-time curves were recorded. The effects of temperature and test vessel volume on various explosion characteristics, such as the maximum explosion pressure, maximum rate of pressure rise, deflagration index, and the lower and upper explosion limits were investigated and the results were further compared with the results available in literature for other alcohols, namely methanol, ethanol, 1-butanol, and 1-pentanol. The most important results from evaluated experiments are the values of deflagration index $89-98 \mathrm{bar} \cdot \mathrm{m} / \mathrm{s}$ for 2-propanol and 105-108 bar.m/s for 1-propanol/2-propanol-air mixtures. These values are used to describe the effect of isomer blends on a deflagration process and to rate the effects of an explosion.
\end{abstract}

Keywords: explosion characteristics; vessel; mixtures; propanol; isomers

\section{Introduction}

Increasing attention has been paid to the use of non-petroleum-based fuels, preferably from renewable sources, including alcohols with up to five carbon atoms. These alcohols are successful in the practical use as gasoline and diesel fuel additives and this has motivated the full investigation of their combustion chemistry [1-4].

Compared to methanol and ethanol, propanol has many superior properties as an alternative fuel (lower hygroscopicity, higher boiling point, and higher energy density). Compared to butanol and pentanol, propanol has a higher percent oxygen content in the molecule. Due to propanol's isomeric structure its combustion properties could be even further tuned by its blends with no change in the fuel's physical-chemical properties [5-8].

Apart from the bio-fuel interest, alcohol fuels use involves critically evaluating their combustion and explosion characteristics under various conditions. Devastating chemical accidents can occur in chemical storage and process industry and transport applications as the flammable liquid expands and increases the risk of vapor cloud explosion. Such accidents have essential social and economic impact $[9,10]$.

Explosion of vapors in closed vessel is a complex process involving fuel atomisation, vaporisation, mixing, ignition and combustion. To characterize this effect and to develop the effective explosion protection systems against overpressure the key closed-vessel deflagration characteristics are used: maximum explosion pressure, $\mathrm{p}_{\max }$, maximum rate of pressure rise, $(\mathrm{dp} / \mathrm{dt})_{\max }$ and the deflagration index, $\mathrm{K}_{\mathrm{G}}[11-16]$. 
Small-scale characterisation in the gas phase towards understanding explosion deflagration over a range of fuel concentrations, temperatures and pressures has been published starting from 2009. Zhang et al. presented a study on the explosion characteristics of methanol-air premixed mixtures in a $5.5 \mathrm{~L}$ cylindrical vessel for $\Phi=0.7-1.8$, with initial pressures of $0.1 \mathrm{MPa}, 0.25 \mathrm{MPa}, 0.5 \mathrm{MPa}$ and three initial temperatures $(373,423,473 \mathrm{~K})$ [11]. Mitu and Brandes investigated the explosion parameters of methanol-air mixtures measured for initial temperatures of $50{ }^{\circ} \mathrm{C}$ and $150{ }^{\circ} \mathrm{C}$ and initial pressures of $75 \mathrm{kPa}$ and $100 \mathrm{kPa}$ and supplemented the measurements with a calculation for temperatures of 25 and $110^{\circ} \mathrm{C}$ in a $5 \mathrm{~L}$ spherical stainless steel vessel [12]. Li et al. conducted a series of experimental studies on the explosion characteristics of ethanol, 1-butanol, 1-pentanol, 2-pentanol and 3-pentanol with air mixtures at an initial temperature up to $200{ }^{\circ} \mathrm{C}$ and an initial pressure up to $0.75 \mathrm{MPa}$ [13]. Parameters were measured in a cylindrical explosion chamber with a diameter $\mathrm{D}=180 \mathrm{~mm}$ and a length $\mathrm{L}=210 \mathrm{~mm}\left(\mathrm{~V}=5.3 \mathrm{dm}^{3}\right)$. The same authors deepened their research through a comparative study of the explosion characteristics of four isomers of pentanol [14]. More recently, Mitu et al. [15] studied the effect of $0.005 \mathrm{~m}^{3}$ and $0.02 \mathrm{~m}^{3}$ vessel volumes on ethanol-air mixtures for different initial conditions. Later, Mitu et al. investigated ethanol-air mixtures in the presence of different diluents in a $0.02 \mathrm{~m}^{3}$ vessel [16]. Most recently, Skrinsky et al. investigated the influence of temperature and vessel volume on explosion characteristics of 1-propanol-air mixtures in $0.02 \mathrm{~m}^{3}$ and $1.00 \mathrm{~m}^{3}$ closed spherical vessels [8]. The results of these experimental studies are summarized in Table 1.

Table 1. Published $\mathrm{p}_{\max }$ and $\mathrm{K}_{\mathrm{G}}$ values.

\begin{tabular}{ccccccc}
\hline Chemical & $\mathbf{p}_{\max }(\mathbf{b a r})$ & $\begin{array}{c}\mathbf{K}_{\mathbf{G}} \\
(\mathbf{b a r} \cdot \mathbf{m} / \mathbf{s})\end{array}$ & $\begin{array}{c}\text { Volume } \\
\left(\mathbf{m}^{\mathbf{3}}\right)\end{array}$ & $\begin{array}{c}\text { Temperature } \\
\left({ }^{\circ} \mathbf{C}\right)\end{array}$ & $\begin{array}{c}\text { Equivalence } \\
\text { Ratio }\end{array}$ & Reference \\
\hline $\mathrm{CH}_{3} \mathrm{OH}$ & $7.1-8.2$ & $105-107$ & $0.005-0.020$ & $50-100$ & $1.00-1.26$ & {$[11,12]$} \\
$\mathrm{C}_{2} \mathrm{H}_{5} \mathrm{OH}$ & $7.9-8.7$ & $95-135$ & $0.005-0.020$ & $100-120$ & $1.00-1.10$ & {$[15,16]$} \\
$1-\mathrm{C}_{3} \mathrm{H}_{7} \mathrm{OH}$ & $7.7-8.7$ & $86-97$ & $0.020-1.000$ & $50-150$ & 1.06 & {$[8]$} \\
$1-\mathrm{C}_{4} \mathrm{H}_{9} \mathrm{OH}$ & $5.5-5.7$ & $95-100$ & $0.0053^{1}$ & 120 & 1.00 & {$[13]$} \\
$1-\mathrm{C}_{5} \mathrm{H}_{11} \mathrm{OH}$ & $5.6-5.7$ & $90-95$ & $0.0053^{1}$ & $120-160$ & 1.00 & {$[13,14]$} \\
\hline \multicolumn{7}{c}{${ }^{1}$ lengths/diameter $=1.17}$.
\end{tabular}

In comparison with Table 1 for the 2-propanol isomer and 1-propanol/2-propanol blends, no studies are available. Objective of this paper is to describe the explosion characteristics of 2-propanol isomer mixtures with air with different equivalence ratios, depending on three initial temperatures of $50{ }^{\circ} \mathrm{C}$, $100{ }^{\circ} \mathrm{C}$, and $150{ }^{\circ} \mathrm{C}$ and two volumes $\left(0.02\right.$ and $\left.1.00 \mathrm{~m}^{3}\right)$. Emphasis is given on the deflagration index of propanol isomer-air mixtures directly obtained by explosion experiments in volume of $1.00 \mathrm{~m}^{3}$. Based on the knowledge of these characteristics, it is possible to evaluate the influence of the carbon chain structure and blending ratio on the explosion characteristics of these alcohol mixtures and compare them with the values from small-scale experiments. This work allowed a systematic comparison and extending knowledges about the explosion properties among C1-C5 alcohols.

\section{Experimental Setup and Chemicals}

Explosion characteristic values of the pure liquids and their binary mixtures were determined experimentally according to the EN 15967:2011 [17] and EN 1839:2017 [18] standards. Two methods were used in the present study; both of them were conducted at the VSB-Technical University of Ostrava [8]. One was the $0.02 \mathrm{~m}^{3}$ (SN: 497-OZM-15, OZM Research, s.r.o., Hrochi̊v Týnec, Czech Republic) oil-heated spherical vessel setup to record pressure-time curves between 50 and $150{ }^{\circ} \mathrm{C}$. The other was the $1.00 \mathrm{~m}^{3}$ (SN: 284-OZM-12-01, OZM Research, s.r.o.) electro-heated spherical vessel setup. Both test apparatuses consisted of a test vessel, an external heating system, a setup for special atmosphere development (vacuum pump, dispersion nozzle, and high-pressure air), pressure and flash measuring systems, a discharge type ignition system, a temperature measuring device, a user interface, and a data storage system. The test vessels were designed to withstand a working pressure of 30 bar. For testing, the explosion vessels were heated to the desired temperatures of $50-150{ }^{\circ} \mathrm{C}$. 
The $0.02 \mathrm{~m}^{3}$ apparatus incorporated a digitally adjustable external control device Presto A30 (SN: 10291377, JULABO GmbH, Seelbach, Germany) that heated the oil in the instrument to the specified temperature range. The $1.00 \mathrm{~m}^{3}$ apparatus used an electro-heated system with a power of $25 \mathrm{~kW}$ (HT Industry, HTH8, Polička, Czech Republic). The initial temperature of mixtures was measured with an accuracy of within $1 \mathrm{~K}$. The test mixture was prepared by a partial pressure method with maximum sampling uncertainty $\pm 0.2 \%$. The evaporation of samples in both vessels was supported by two systems. First, the procedure started with evacuation to the initial conditions under a pressure of 0.40 bar in the $0.02 \mathrm{~m}^{3}$ setup or 0.89 bar in the $1.00 \mathrm{~m}^{3}$ apparatus. The sample was blown into the evacuated chamber by a dispersion pressure of 5 bar in both vessels. Second, the dispersion nozzle for aerosol generation was used. This combination was applied to effectively evaporate the samples, especially at temperatures below $84{ }^{\circ} \mathrm{C}$ (the boiling point of 2-propanol). In the $0.02 \mathrm{~m}^{3}$ system the dynamic pressure in the vessel was measured by a pair of quartz pressure sensors (SN: 4512821 and SN: 4512822, model 701A, Kistler, Winterthur, Switzerland) and recorded with a charge amplifier (Kistler, model 5041E0). In the $1.00 \mathrm{~m}^{3}$ system the dynamic pressure in the vessel was measured by a pair of quartz pressure sensors (SN: 4353089 and SN: 4353090, Kistler, model 701A) and recorded with a charge amplifier (SN: 50734370760, Kistler, model 5073). The pressure measuring range for the sensors was within 25 bar. The data acquisition sampling period was $0.02 \mathrm{~ms}$ with a sampling frequency $50 \mathrm{kS} / \mathrm{s}$. Programmable logic controllers (model 1215 in $1.00 \mathrm{~m}^{3}$ and 5073A211 in $0.02 \mathrm{~m}^{3}$, Siemens, Munich, Germany) connected to a PC were used with the interface (PROMOTIC system, MICROSYS, spol. s.r.o., Ostrava, Czech Republic) to automatically control the whole testing procedure. Both experimental setups are schematically introduced in Figures 1 and 2.

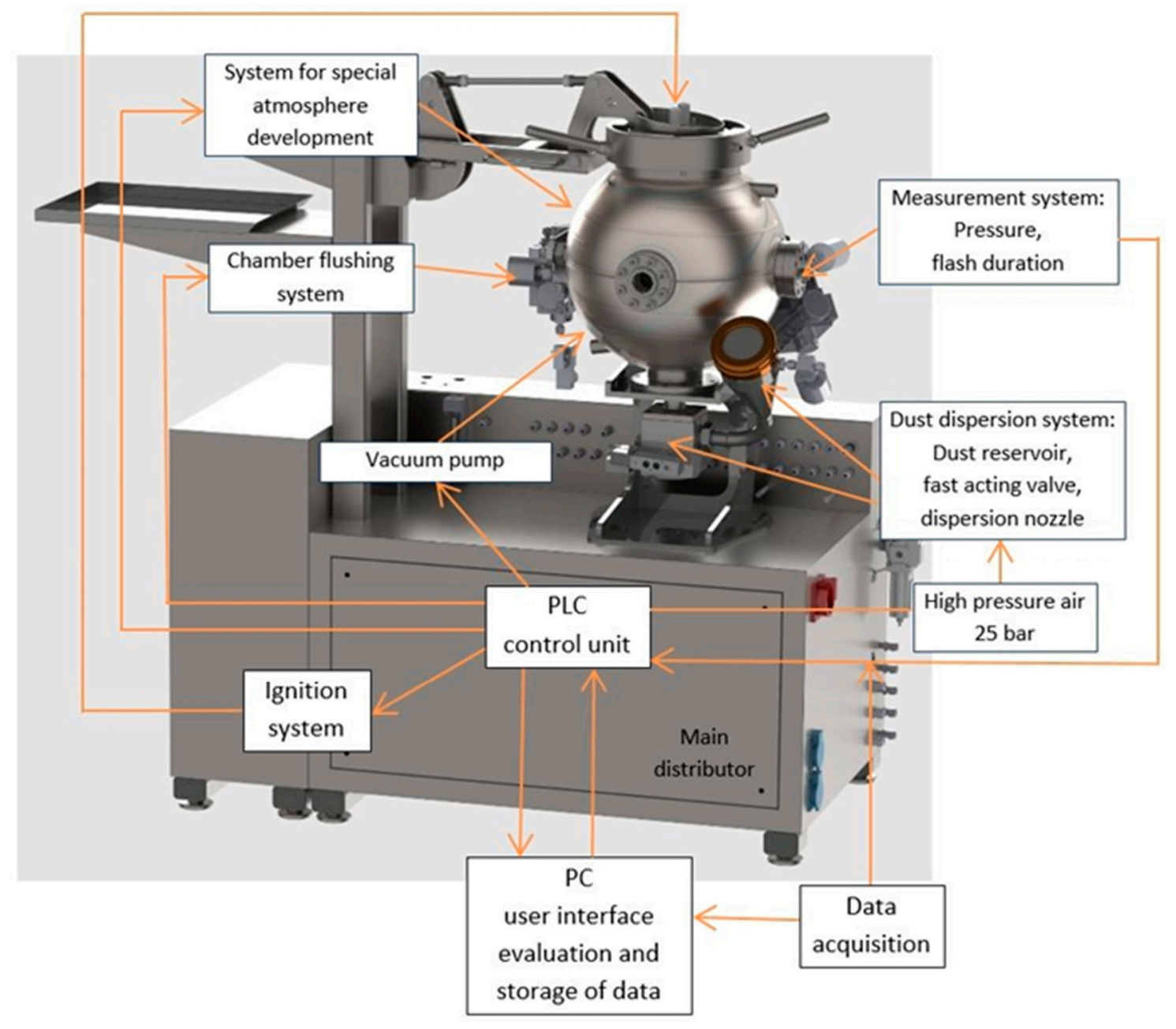

Figure 1. Experimental setup of the $0.02 \mathrm{~m}^{3}$ spherical vessel. 


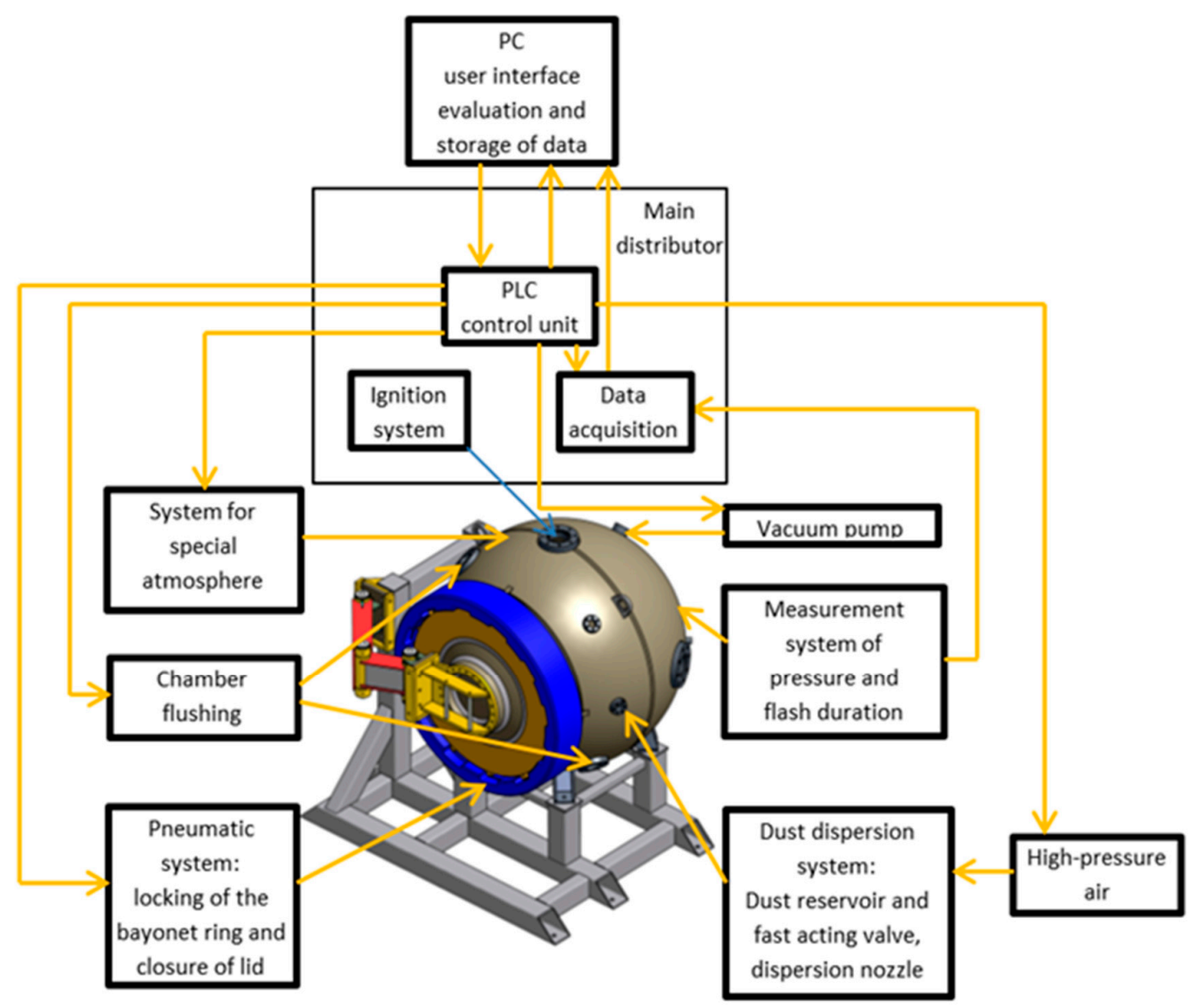

Figure 2. Experimental setup of the $1.00 \mathrm{~m}^{3}$ spherical vessel.

The properties of the experimental materials used are summarized in Table 2.

Table 2. Physical properties of experimental materials.

\begin{tabular}{cccc}
\hline Chemical & Formula & Purity (Mass \%) & Company \\
\hline 1-propanol & $\mathrm{C}_{3} \mathrm{H}_{7} \mathrm{OH}$ & $>99.7$ & Merck KGaA (Darmstadt, Germany) \\
2-propanol & $\mathrm{C}_{3} \mathrm{H}_{7} \mathrm{OH}$ & $>99.8$ & Penta (Katowice, Poland) \\
\hline
\end{tabular}

\section{Data Evaluation}

The $p_{\text {ex }}$ was determined as the highest value of the pressure-time curve divided by the initial pressure for the actual equivalence ratio. The $\mathrm{p}_{\max }$ is the highest explosion pressure for all equivalence ratios divided by the initial pressure [17]. The value of $(\mathrm{dp} / \mathrm{dt})_{\max }$ decreases with increasing vessel volume. Therefore, $(\mathrm{dp} / \mathrm{dt})_{\max }$ is for $0.02 \mathrm{~m}^{3}$ recalculated to a vessel volume $(\mathrm{V})$ of $1 \mathrm{~m}^{3}$, using Equation (1) for the deflagration index:

$$
\mathrm{K}_{\mathrm{G}}=\mathrm{V}^{1 / 3} \cdot(\mathrm{dp} / \mathrm{dt})_{\max } .
$$

The maximum explosion pressures, the deflagration indexes, and the explosion delay times were obtained from pressure time records. Upper explosion limit, UEL, and lower explosion limit, LEL, evaluation is based on the highest and lowest concentrations, respectively, at which the material is explosive by using the $5.0 \mathrm{vol} . \%$ criterion [18]. The explosion delay time, $\mathrm{t}_{\mathrm{ex}}$, is the time at which the maximum explosion pressure is reached [15].

The experimental uncertainty in a statistical sense is given by the used experimental method and is 10\% for explosion characteristics according to EN 15967:2011 [17]. The flammable substance content in 
the test mixture lies within an uncertainty of measurement of $\pm 10 \%$ relative for a flammable substance content up to $2 \mathrm{~mol} . \%$, and $+0.2 \%$ absolute for a flammable substance content above $2 \mathrm{~mol} . \%$ according to EN 1839:2017 [18]. With 2-propanol and 1-propanol/2-propanol in air mixtures 3 measurements were performed for each sample concentration at $\mathrm{T}_{0}=50-150{ }^{\circ} \mathrm{C}$ and $\mathrm{p}_{0}=1$ bar. For example, with the composition of 7.0 vol.\% 2-propanol in air, 3 tests were performed in $0.02 \mathrm{~m}^{3}$ at $\mathrm{T}_{0}=50^{\circ} \mathrm{C}$ and $\mathrm{p}_{0}=1$ bar. $P_{\mathrm{ex}}$ was determined to be $8.69 \mathrm{bar} \pm 0.14 \mathrm{bar},(\mathrm{dp} / \mathrm{dt})_{\mathrm{ex}}$ to be $349.2 \mathrm{bar} / \mathrm{s} \pm 24.1 \mathrm{bar} / \mathrm{s}, \mathrm{K}_{\mathrm{G}}$ to be 94.6 $\pm 6.5 \mathrm{bar} \cdot \mathrm{m} / \mathrm{s}$ and $\mathrm{t}_{\mathrm{ex}}$ to be $89.0 \pm 3.7 \mathrm{~ms}$. As a result the mean values $8.7 \mathrm{bar}, 349 \mathrm{bar} / \mathrm{s}, 95 \mathrm{bar} \cdot \mathrm{m} / \mathrm{s}$ and $89.0 \mathrm{~ms}$ were taken for further evaluations. The maximum measurement uncertainties obtained for $p_{e x},(\mathrm{dp} / \mathrm{dt})_{e x}$ and $t_{\text {ex }}$ are given in Table 3.

Table 3. Maximum measurement uncertainty.

\begin{tabular}{|c|c|c|c|c|c|c|c|c|c|c|c|c|}
\hline \multirow[b]{3}{*}{$\mathrm{T}_{0}\left({ }^{\circ} \mathrm{C}\right)$} & \multicolumn{6}{|c|}{$0.02 \mathrm{~m}^{3}$} & \multicolumn{6}{|c|}{$1 \mathrm{~m}^{3}$} \\
\hline & \multicolumn{3}{|c|}{ 2-Propanol } & \multicolumn{3}{|c|}{ 1-Propanol/2-Propanol } & \multicolumn{3}{|c|}{ 2-Propanol } & \multicolumn{3}{|c|}{ 1-Propanol/2-Propanol } \\
\hline & $p_{\max }$ & $\mathrm{K}_{\mathrm{G}}$ & $t_{e x}$ & $p_{\max }$ & $\mathbf{K}_{\mathrm{G}}$ & $t_{e x}$ & $p_{\max }$ & $\mathbf{K}_{\mathrm{G}}$ & $t_{e x}$ & $p_{\max }$ & $\mathrm{K}_{\mathrm{G}}$ & $t_{e x}$ \\
\hline 50 & $1.6 \%$ & $6.9 \%$ & $4.2 \%$ & $1.7 \%$ & $7.1 \%$ & $4.5 \%$ & $1.9 \%$ & $7.9 \%$ & $4.9 \%$ & $1.8 \%$ & $7.2 \%$ & $4.6 \%$ \\
\hline 100 & $2.0 \%$ & $7.0 \%$ & $5.0 \%$ & $2.1 \%$ & $8.0 \%$ & $5.1 \%$ & $2.2 \%$ & $7.2 \%$ & $5.2 \%$ & $2.3 \%$ & $8.2 \%$ & $5.3 \%$ \\
\hline 150 & $2.2 \%$ & $8.4 \%$ & $5.1 \%$ & $2.1 \%$ & $8.5 \%$ & $5.2 \%$ & $2.2 \%$ & $8.5 \%$ & $5.3 \%$ & $2.4 \%$ & $8.5 \%$ & $5.6 \%$ \\
\hline
\end{tabular}

The measurement uncertainties in Table 3 are well within the respective ranges given in EN 15967:2011 [17]. The maximum experimental uncertainty for LEL and UEL was taken $0.2 \%$ absolute. The pressure-time curves were smoothed to remove noises from the signal using the Savitzky-Golay method [19] by signal processing polynomial functions implemented in the OriginPro 8 program [20]. To perform smoothing we used 20 points of windows with a periodic boundary condition for the fifth polynomial order optimized by R-squared maximization. The pressure-time curve changed little after the smoothing process but the maximum rate of pressure rose, change greatly. Figure 3 illustrates the comparison of the raw and filtered data for the pressure-time curve determination of the explosion pressure rise.

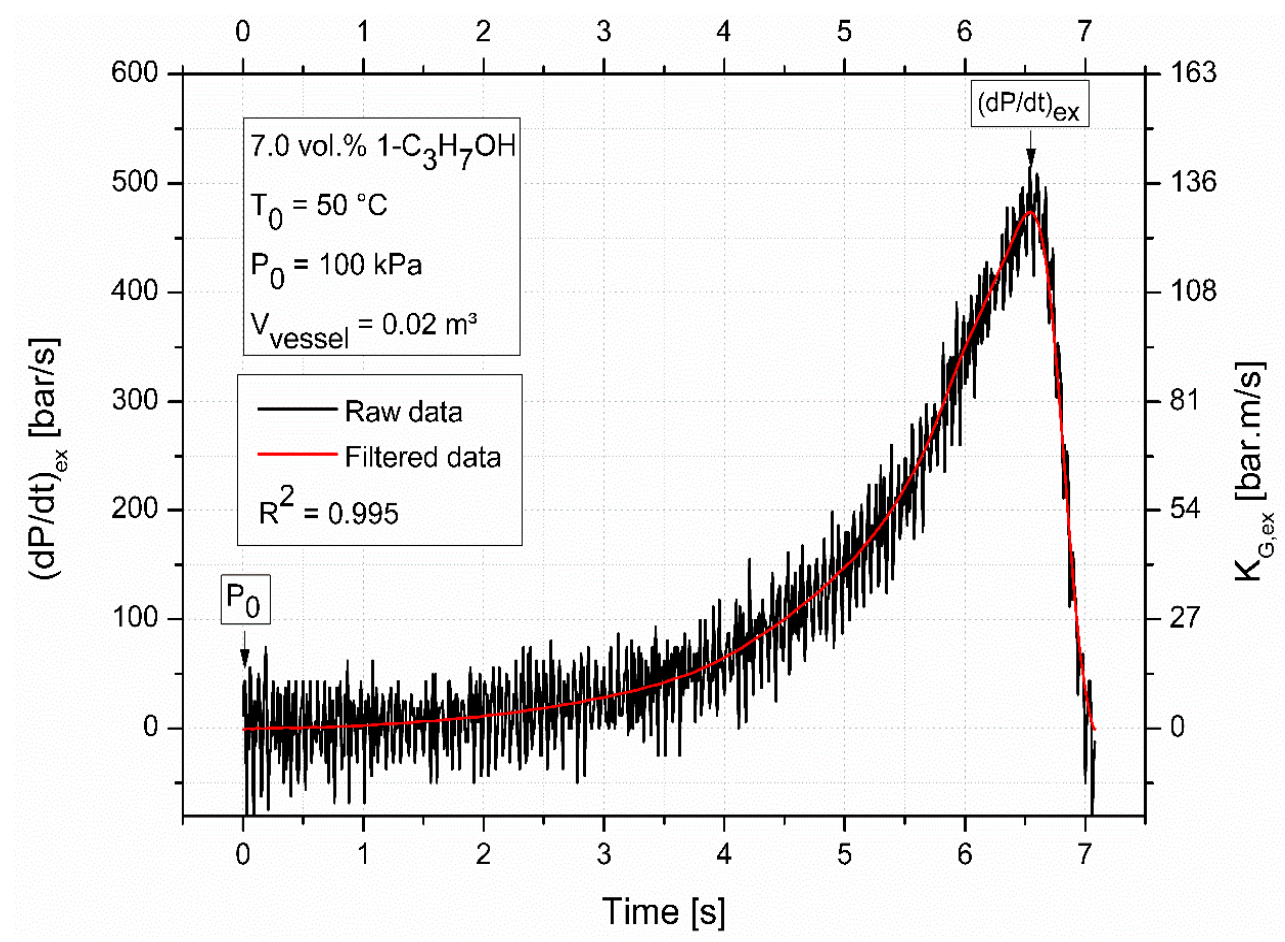

Figure 3. An illustration of the smoothing filter on the pressure-time curve determination of the explosion pressure rise. 


\section{Results and Discussion}

\subsection{Influence of Temperature}

The influence of temperature on explosion pressures at 11 concentrations for pure 1-propanol-air mixtures have been described in [8]. The results of 1-propanol-air mixtures were used to predict the initial values for pure 2-propanol-air measurements, as presented in Figures 4 and 5.

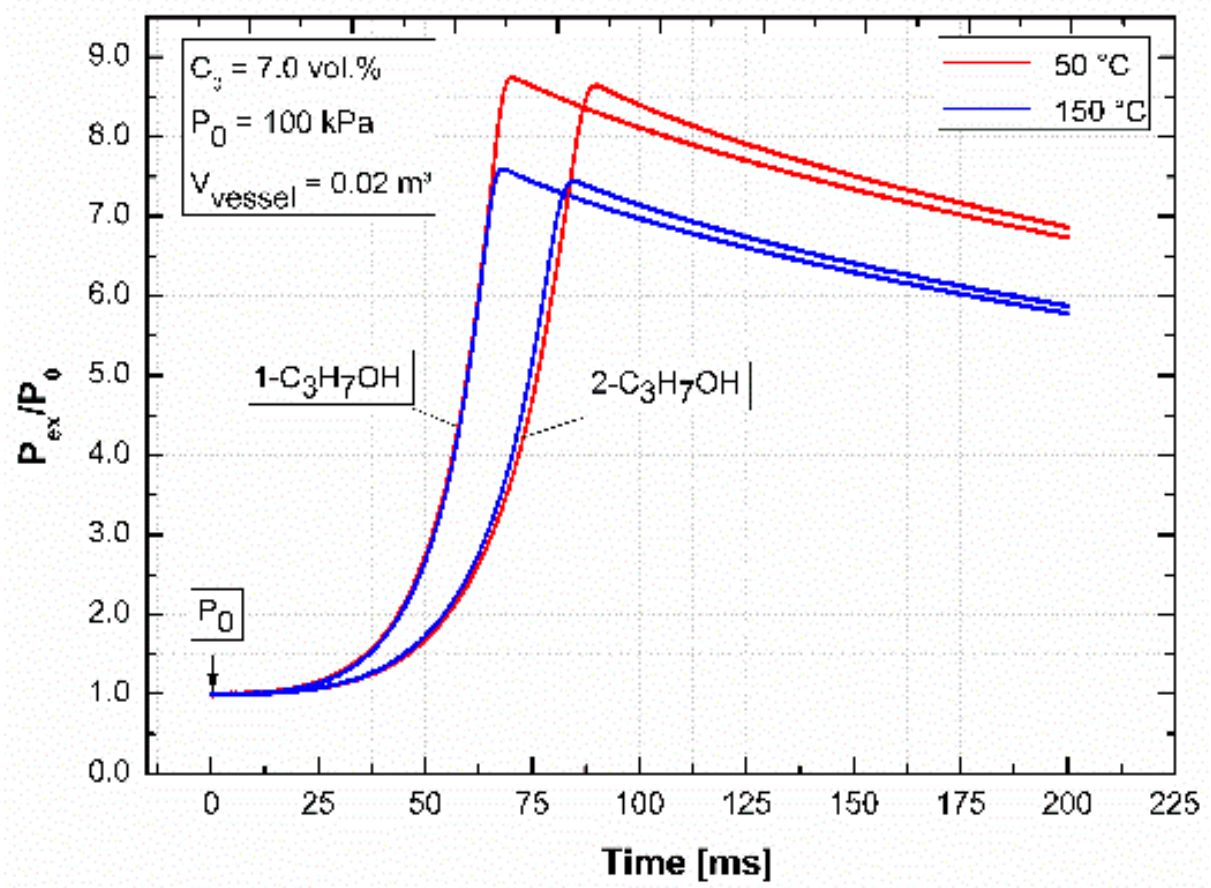

Figure 4. $\mathrm{p}_{\mathrm{ex}} / \mathrm{p}_{0} /$ time for 1-propanol and 2-propanol deflagration in a $0.02 \mathrm{~m}^{3}$ vessel, $\mathrm{p}_{0}=100 \mathrm{kPa}$.

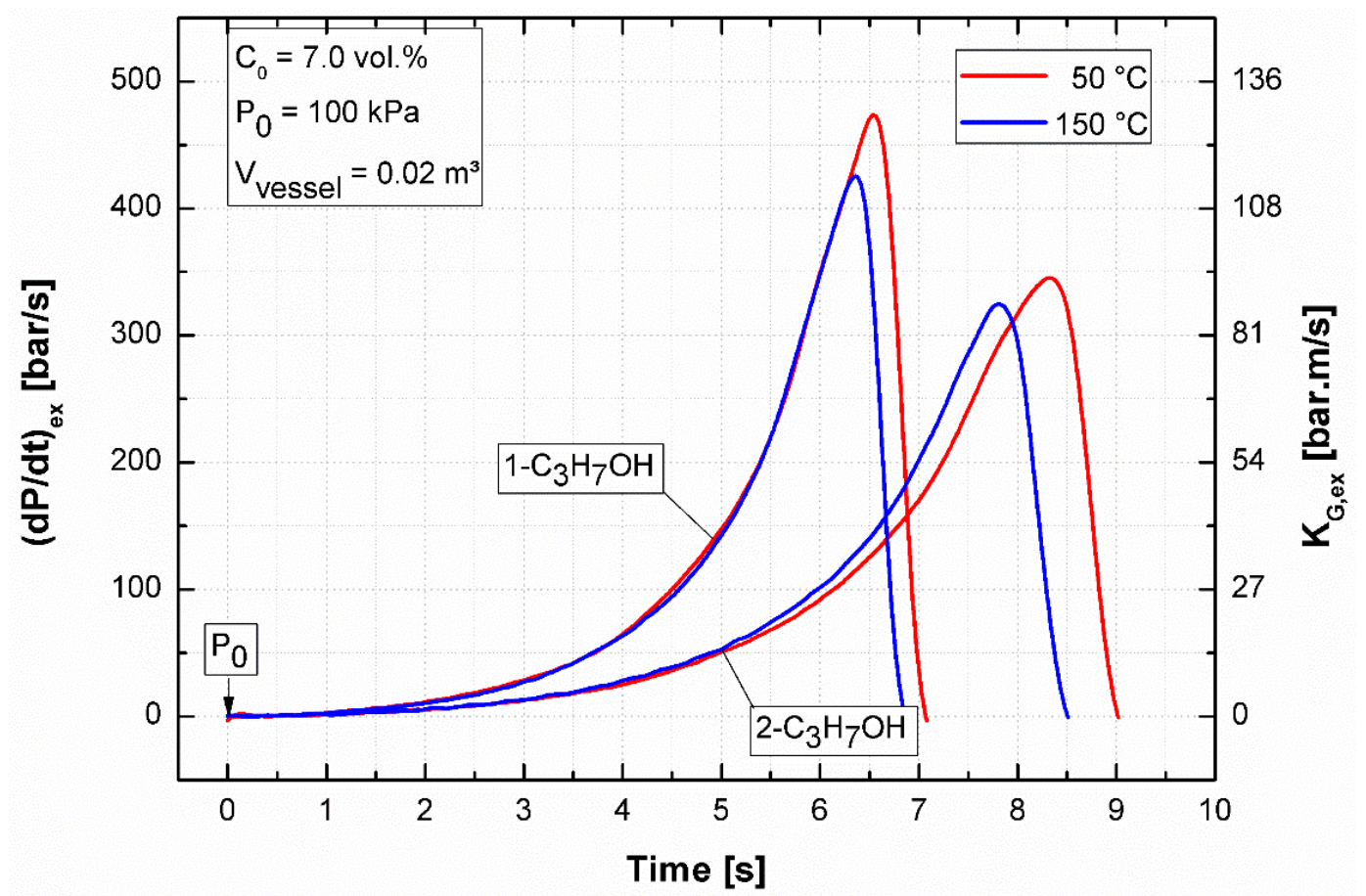

Figure 5. $(\mathrm{dp} / \mathrm{dt})_{\max } /$ time for 1-propanol and 2-propanol deflagration in a $0.02 \mathrm{~m}^{3}$ chamber, $\mathrm{p}_{0}=100 \mathrm{kPa}$. 
Figure 4 illustrates the effects of initial temperature on the explosion pressure, explosion rate of pressure rise, and explosion delay time of 1-propanol and 2-propanol at the initial temperatures of 50 and $150{ }^{\circ} \mathrm{C}$, atmospheric pressure, a $\mathrm{p}_{0}$ of $100 \mathrm{kPa}$, and the same equivalence ratio, $\phi=1.06$. With increasing temperature, the explosion pressure decreased and the explosion delay time slightly decreased for both isomers. The explosion pressure changes only slightly in the maximum values when comparing 1-propanol and 2-propanol for both temperatures.

Figure 5 gives the measured explosion pressure rise-time curves of 1-propanol and 2-propanol for near-stoichiometric equivalence ratios and initial temperatures of 50 and $150{ }^{\circ} \mathrm{C}$. With the increased initial temperature, the values of the maximum rates of pressure rise decreased for both isomers. The results of the rate of pressure rise-time curve fits well with the data for ethanol published in [15] and data for $\mathrm{C}_{\mathrm{n}} \mathrm{H}_{2 \mathrm{n}+1} \mathrm{OH}(\mathrm{n}=1,2,4,5)[13]$.

\subsection{Influence of Volume and Isomer Structure}

Figures 6 and 7 plot examples of the normalized explosion pressure, $\mathrm{p}_{\max } / \mathrm{p}_{0}$, versus the equivalence ratio for 2-propanol-air and 1-propanol/2-propanol-air mixtures. The normalized explosion pressures were obtained at two vessel volumes $\left(0.020 \mathrm{~m}^{3}\right.$ and $\left.1.00 \mathrm{~m}^{3}\right)$ and three initial temperatures $(50,100$, and $\left.150{ }^{\circ} \mathrm{C}\right)$.

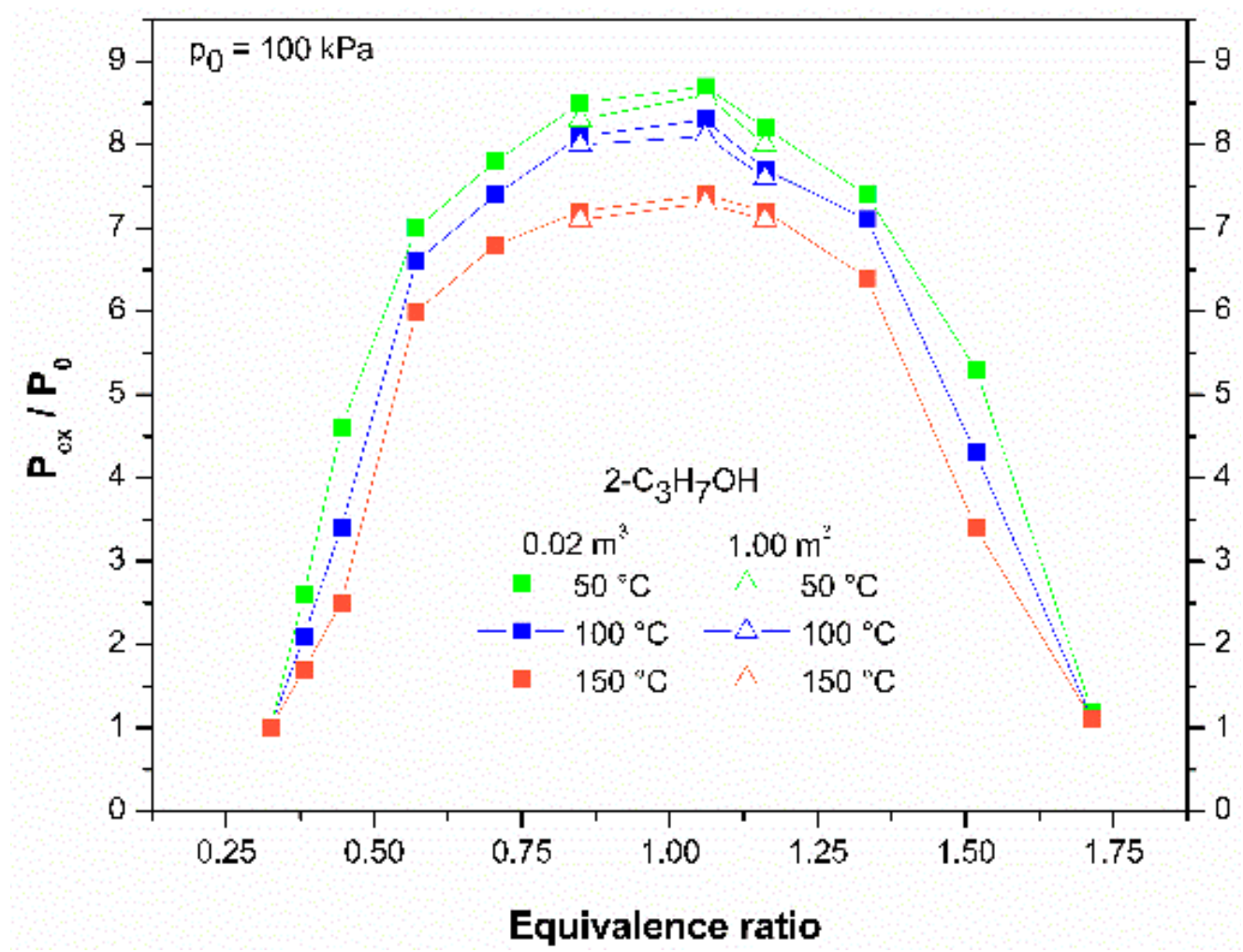

Figure 6. $\mathrm{p}_{\mathrm{ex}} / \mathrm{p}_{0}$ versus $\Phi=0.3-1.7$ for 2-propanol-air mixtures at various initial volumes, temperatures, and mixture compositions, $\mathrm{p}_{0}=100 \mathrm{kPa}$. 


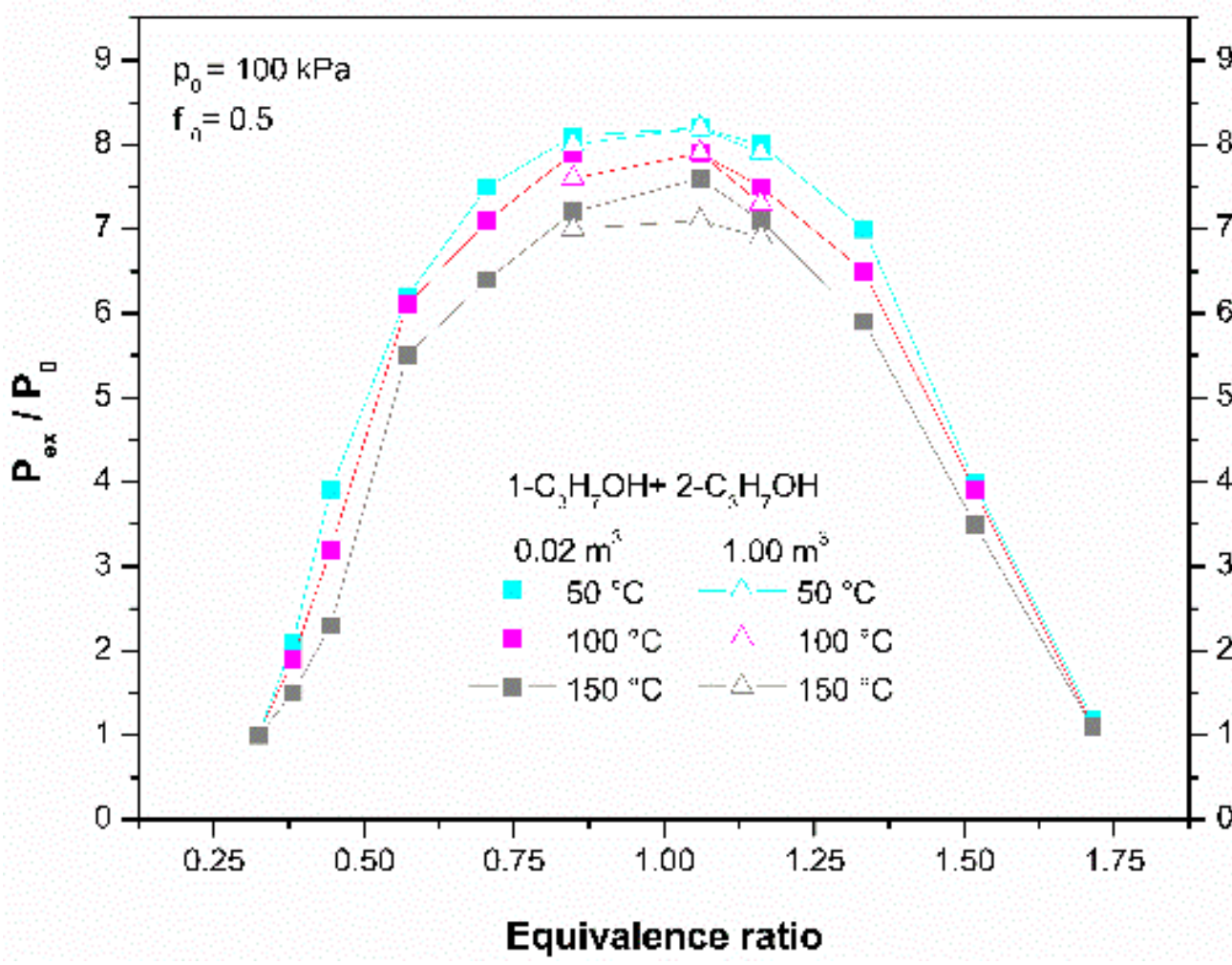

Figure 7. $\mathrm{p}_{\mathrm{ex}} / \mathrm{p}_{0}$ versus $\Phi=0.3-1.7$ for 1-propanol/2-propanol-air mixtures $\left(\mathrm{f}_{0}=0.5\right)$ at various initial volumes, temperatures, and mixture compositions, $\mathrm{p}_{0}=100 \mathrm{kPa}$.

The tested vessel volumes did not significantly influence the values of the explosion pressure. The maximum explosion pressure measured in the $0.02 \mathrm{~m}^{3}$ vessel showed the same trend and was slightly higher at $150{ }^{\circ} \mathrm{C}$ than the maximum explosion pressure measured in the $1.00 \mathrm{~m}^{3}$ vessel. For the equivalence ratio of $\Phi=1.00$ and the initial temperature $150{ }^{\circ} \mathrm{C}$, the values of $p_{\max }$ were $7.6 \mathrm{bar}$ and 7.1 bar. Comparable results, as shown in Figure 6, have been reported in [8] for 1-propanol-air deflagrations and in [15] for ethanol-air mixtures at various initial temperatures, mixture compositions, and $\mathrm{p}_{0}=100 \mathrm{kPa}$. The experiments of both propanol isomer-air mixtures had equivalence ratios of $\Phi=0.3-1.7$. The maximum value of the explosion pressure for 2-propanol was found at $\Phi=1.06$ for all temperatures. This means that isomer equivalence ratios corresponding to the maximum explosion pressures are not influenced by the initial temperature. The measured results for $p_{\text {ex }}$ values show a reasonable agreement at near-stoichiometric concentrations with the four pentanol isomer-air mixtures from previous studies [14] measured in $0.005 \mathrm{~m}^{3}$ at $160{ }^{\circ} \mathrm{C}$.

The shape of the explosion pressure versus 1-propanol/2-propanol-air equivalence ratio at different initial temperatures with varying concentrations was similar at all investigated initial temperatures, as for pure 2-propanol and pure 1-propanol [8]. The maximum value of the explosion pressure was found at $\Phi=1.06$ for both volumes and all temperatures. The increase in the initial temperature lowers the explosion pressure, as discussed in [12]. At equivalence ratios close to the LEL and UEL, the values of $\mathrm{p}_{\mathrm{ex}} / \mathrm{p}_{0}$ decrease to the value close to initial pressure. After reaching this concentration the explosion can no longer propagate. The explosion pressures closer to the upper explosion limit decrease more than in pure 2-propanol-air but similar to the trend observed for pure 1-propanol-air. Figures 6 and 7 indicate the tendency of 2-propanol to lower the explosion pressure of the 1-propanol/2-propanol-air mixture. The presence of the $\mathrm{OH}$ group in the second carbon of the 2-propanol molecule makes this result interesting to compare with 1-propanol, which has the $\mathrm{OH}$ group at the end of the molecule. This effect of propanol is attacked by unstable and reactive species through different mechanisms.

The measured results show good agreement at near-stoichiometric concentrations with the previous 1-propanol studies [8] with a 0.5 bar difference at temperatures $50^{\circ} \mathrm{C}$ and $100^{\circ} \mathrm{C}$. The explosion pressure 
is only slightly dependent on the vessel volume, which plays a role in the assessment of explosion hazard. From these results it was concluded that the isomer structure does not play a significant role in maximum explosion pressure development and for LEL and UEL. The slight difference between $0.02 \mathrm{~m}^{3}$ and $1.00 \mathrm{~m}^{3}$ is attributed to heat lost in the vessel walls [13]. Figure 8 plots a comparison of the pure 1-propanol-air and 2-propanol-air mixtures at various initial temperatures, 11 equivalence ratios, and $\mathrm{p}_{0}=100 \mathrm{kPa}$.

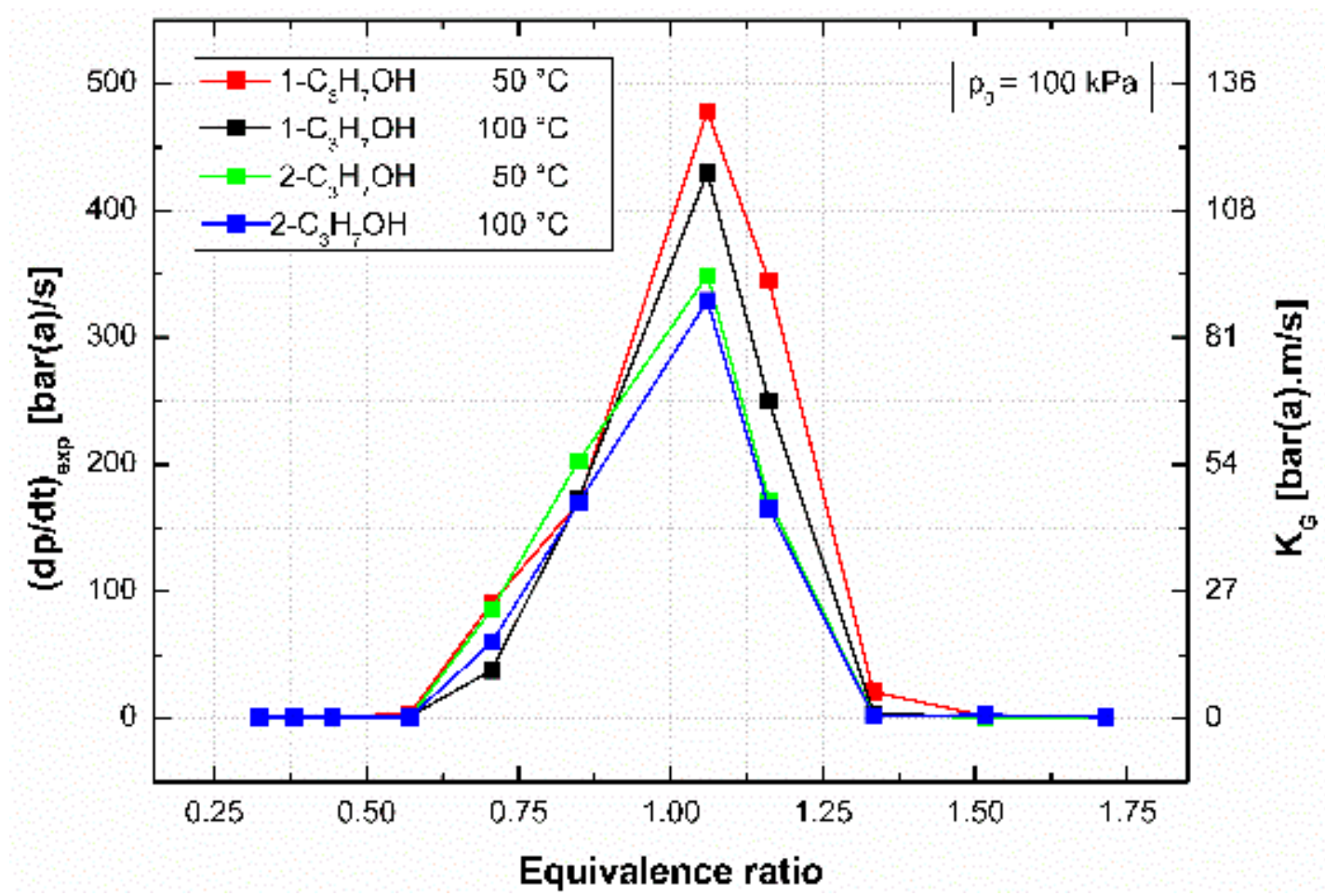

Figure 8. $(\mathrm{dp} / \mathrm{dt})_{\mathrm{ex}}$ versus $\Phi=0.3-1.7$ for propanol isomer-air mixtures at various initial temperatures and mixture compositions, $\mathrm{p}_{0}=100 \mathrm{kPa}$.

The rate of pressure rise reached the maximum at $\Phi=1.06(7.0 \pm 0.2 \mathrm{vol} . \%)$ for both volumes and all temperatures. The maximum rate of pressure rise for 2-propanol is in good agreement with the values published for hydroxyl-substituted $\mathrm{C}_{n} \mathrm{H}_{2 n+1} \mathrm{OH}$ analogues (where $\mathrm{n}=1-5$ ) in [13]. Table 4 shows that there is only a slight difference in the trend presented due to the explosion vessel volume according to the deflagration index values.

Table 4. 2-propanol explosion characteristics at $\Phi=1.06, \mathrm{p}_{0}=100 \mathrm{kPa}$.

\begin{tabular}{cccccccc}
\hline \multirow{2}{*}{ Characteristic } & \multirow{2}{*}{ Unit } & \multicolumn{3}{c}{$\mathbf{0 . 0 2}^{\mathbf{3}}$} & \multicolumn{3}{c}{$\mathbf{1 . 0 0 ~}^{\mathbf{3}}$} \\
\cline { 3 - 7 } & & $\mathbf{5 0}{ }^{\circ} \mathbf{C}$ & $\mathbf{1 0 0}{ }^{\circ} \mathbf{C}$ & $\mathbf{1 5 0}^{\circ} \mathbf{C}$ & $\mathbf{5 0}^{\circ} \mathbf{C}$ & $\mathbf{1 0 0}^{\circ} \mathbf{C}$ & $\mathbf{1 5 0}^{\circ} \mathbf{C}$ \\
\hline $\mathrm{p}_{\max } / \mathrm{p}_{0}$ & & $8.7 \pm 0.1$ & $8.3 \pm 0.2$ & $7.4 \pm 0.2$ & $8.6 \pm 0.2$ & $8.1 \pm 0.2$ & $7.3 \pm 0.2$ \\
$(\mathrm{dp} / \mathrm{dt})_{\max }$ & $\mathrm{bar} / \mathrm{s}$ & $349 \pm 24$ & $338 \pm 24$ & $329 \pm 28$ & $361 \pm 29$ & $354 \pm 26$ & $336 \pm 29$ \\
$\mathrm{~K}_{\mathrm{G}}$ & $\mathrm{bar} \cdot \mathrm{m} / \mathrm{s}$ & $95 \pm 7$ & $92 \pm 6$ & $89 \pm 7$ & $98 \pm 7$ & $96 \pm 7$ & $91 \pm 8$ \\
$\mathrm{LEL}^{1}$ & $\%$ & $3.5 \pm 0.2$ & $3.5 \pm 0.2$ & $3.0 \pm 0.2$ & $2.5 \pm 0.2$ & $2.0 \pm 0.2$ & $2.0 \pm 0.2$ \\
$\mathrm{UEL}^{2}$ & $\%$ & $14.0 \pm 0.2$ & $14.0 \pm 0.2$ & $14.5 \pm 0.2$ & $13.0 \pm 0.2$ & $13.0 \pm 0.2$ & $13.5 \pm 0.2$ \\
$\mathrm{t}_{\mathrm{ex}}$ & $\mathrm{ms}$ & $89 \pm 4$ & $87 \pm 4$ & $85 \pm 4$ & $215 \pm 11$ & $181 \pm 9$ & $176 \pm 9$ \\
\hline \multicolumn{6}{c}{${ }^{1}$ Lower explosion limit, ${ }^{2}$ Upper explosion limit. }
\end{tabular}

When the initial temperature changes from 50 to $100{ }^{\circ} \mathrm{C}$, as shown in Figure 8, the maximum rate of pressure rise increases and the difference between the 1-propanol and 2-propanol isomers appears, especially in near-stoichiometric concentrations. There is also some small deviation in the lean explosion mixture concentrations close to the value $\Phi=0.7$. The observed trend is different from 
that described in [21]. Such difference from our results is attributed to the heat losses to the wall in both $0.02 \mathrm{~m}^{3}$ and $1.00 \mathrm{~m}^{3}$ vessels in comparison with the heat lost in a $0.005 \mathrm{~m}^{3}$ vessel, being respectively four and 20 times lower in volume compared to the vessels employed in our experiments.

Values close to the lower explosion limit differ in trend in comparison to the values close to the higher explosion limit. This behavior is influenced by the initial temperature.

Figure 9 shows an example of the rate of pressure rise versus the equivalence ratio under the same initial conditions, i.e., $\mathrm{p}_{0}=1 \mathrm{bar}$ and a blending ratio of 0.5 for two initial temperatures of $50{ }^{\circ} \mathrm{C}$ and $100{ }^{\circ} \mathrm{C}$. The present data of 1-propanol/2-propanol-air mixtures are in good agreement with the explosion characteristics of pentanol isomer-air mixtures [14]. The maximum values of the mixture lie in between the values reported for pure 1-propanol and pure 2-propanol for both initial temperatures.

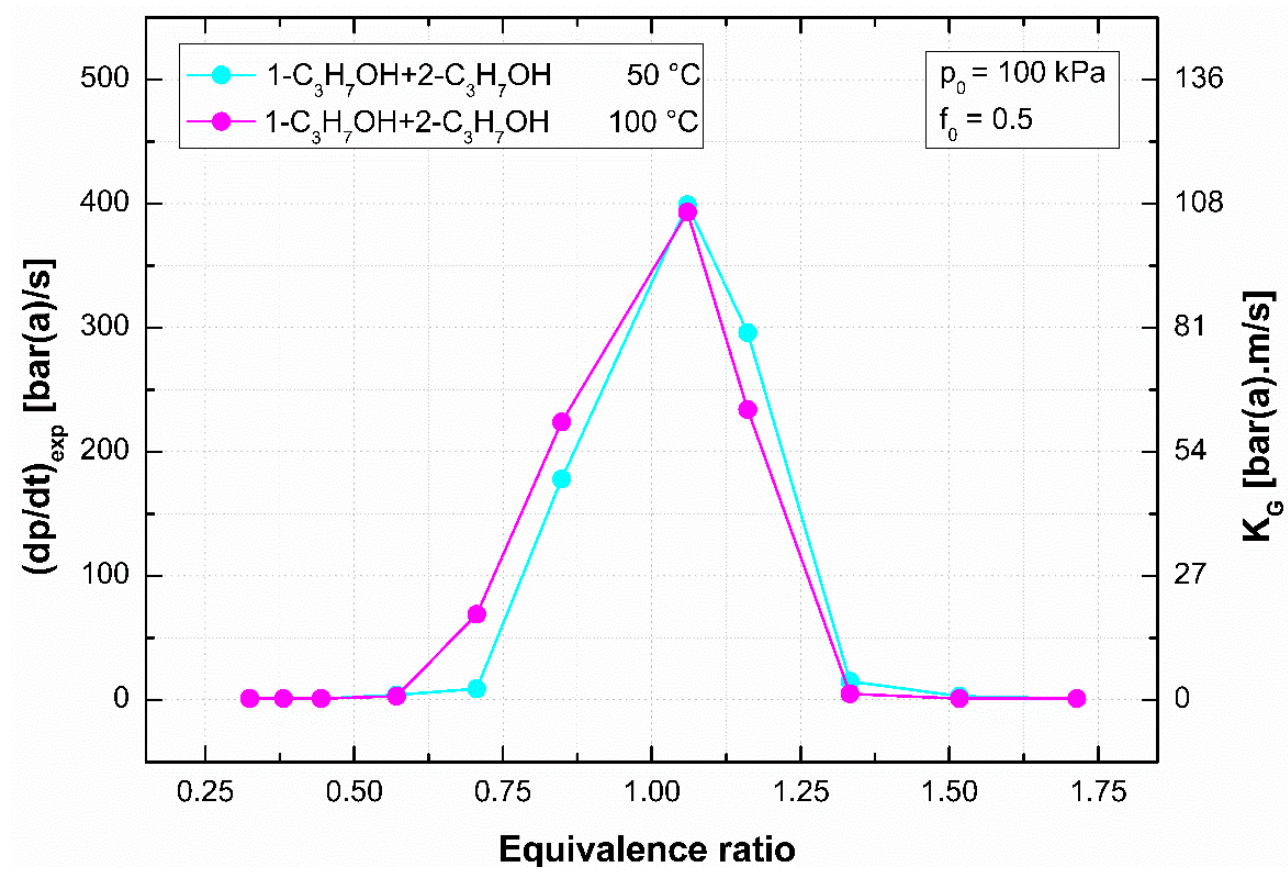

Figure 9. $(\mathrm{dp} / \mathrm{dt})_{\text {ex }}$ versus $\Phi=0.3-1.7$ for 1-propanol/2-propanol-air mixtures $\left(\mathrm{f}_{0}=0.5\right)$ at various initial temperatures and mixture compositions, $\mathrm{p}_{0}=100 \mathrm{kPa}$.

Figures 10 and 11 give an example of the combustion delay time characteristic versus 11 equivalence ratios at two initial temperatures, $50^{\circ} \mathrm{C}$ and $100{ }^{\circ} \mathrm{C}$, for pure isomers at $\mathrm{p}_{0}=100 \mathrm{kPa}$ measured in $0.02 \mathrm{~m}^{3}$. The shortest combustion delay times were found at the equivalence ratio $\Phi=1.06$. The presented trends are in agreement with the $\mathrm{C}_{n} \mathrm{H}_{2 n+1} \mathrm{OH}$ analogues (where $\mathrm{n}=1,2,4,5$ ) in [13] and are similar for the $1 \mathrm{~m}^{3}$ explosion vessel volume.

Figure 11 illustrates the effect of blending on time to reach the explosion maximum characteristics. Physicochemical properties of pure alcohols influenced the explosion delay time mainly in lean and rich regions. The explosion delay time of the 1-propanol/2-propanol-air mixture is influenced by the mixture's individual components. Especially in the lean region, the explosion delay time is mainly influenced by the behavior of 2-propanol.

Figures 10 and 11 show that the time to reach the maximum explosion pressure at lean and rich explosion mixtures decreased with increasing initial temperature and fixed initial pressure for both pure alcohols and their mixtures. The results reveal that the minimum explosion delays times are only slightly influenced by the different chemical structures of the studied isomers. The lowest value of explosion delay time is near the stoichiometric ratio for both the 0.02 and $1.00 \mathrm{~m}^{3}$ volumes. Figures $8-11$ show that with the increase of the initial temperature, the rate of explosion pressure rise decreased and the explosion duration decreases. The rate of explosion pressure rise and the explosion delay time 
have reverse effects. The maximum rate of explosion pressure rise does not have the same trend with increasing initial temperature for lean 1-propanol/2-propanol-air mixtures.

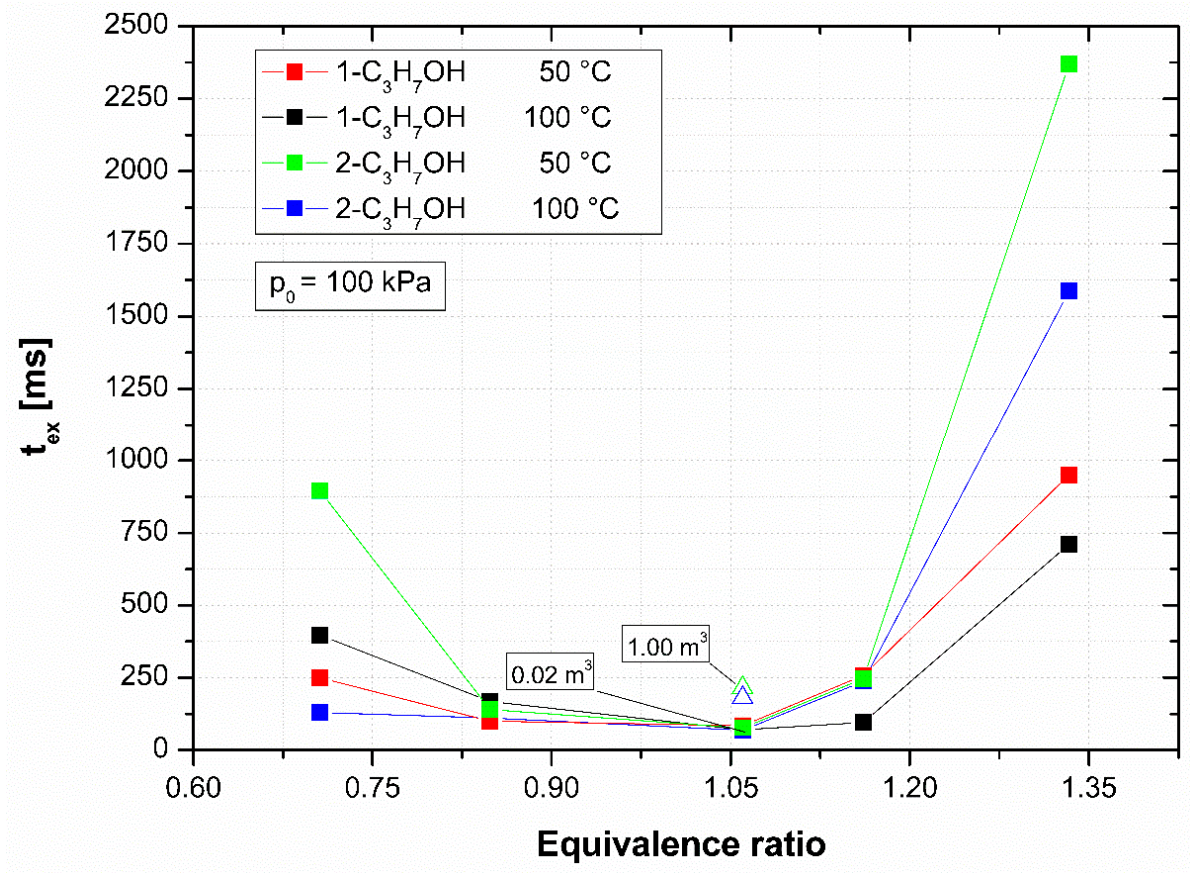

Figure 10. $t_{\text {ex }}$ versus $\Phi=0.7-1.3$ for propanol isomer-air mixtures at various initial temperatures and mixture compositions, $\mathrm{p}_{0}=100 \mathrm{kPa}$.

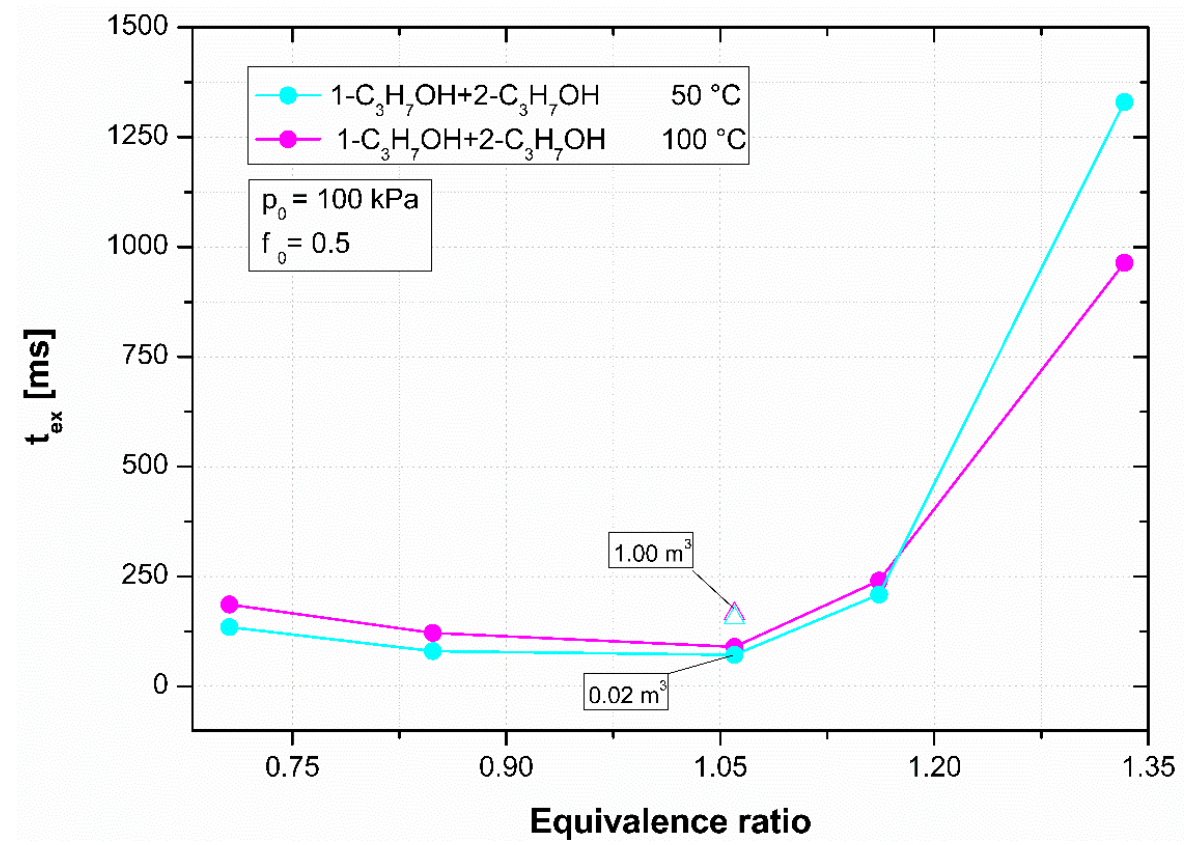

Figure 11. $t_{\text {ex }}$ versus $\Phi=0.7-1.3$ for 1-propanol/2-propanol-air mixtures at various initial temperatures and mixture compositions, $\mathrm{p}_{0}=100 \mathrm{kPa}$.

Tables 4 and 5 present the experimentally derived data of 2-propanol and 1-propanol/2-propanol-air mixtures in 0.02 and $1.00 \mathrm{~m}^{3}$ vessel volumes for three initial temperatures of $50^{\circ} \mathrm{C}, 100^{\circ} \mathrm{C}$, and $150^{\circ} \mathrm{C}$. 
Table 5. 1-propanol/2-propanol-air mixture explosion characteristics at $\Phi=1.06, \mathrm{p}_{0}=100 \mathrm{kPa}$.

\begin{tabular}{cccccccc}
\hline \multirow{2}{*}{ Characteristic } & \multirow{2}{*}{ Unit } & \multicolumn{3}{c}{$\mathbf{0 . 0 2} \mathbf{~ m}^{\mathbf{3}}$} & \multicolumn{3}{c}{$\mathbf{1 . 0 0 ~}^{\mathbf{3}}$} \\
\cline { 3 - 7 } & & $\mathbf{5 0}{ }^{\circ} \mathbf{C}$ & $\mathbf{1 0 0}{ }^{\circ} \mathbf{C}$ & $\mathbf{1 5 0}^{\circ} \mathbf{C}$ & $\mathbf{5 0}^{\circ} \mathbf{C}$ & $\mathbf{1 0 0}^{\circ} \mathbf{C}$ & $\mathbf{1 5 0}^{\circ} \mathbf{C}$ \\
\hline $\mathrm{p}_{\max } / \mathrm{p}_{0}$ & & $8.2 \pm 0.1$ & $7.9 \pm 0.2$ & $7.6 \pm 0.2$ & $8.2 \pm 0.2$ & $7.9 \pm 0.2$ & $7.1 \pm 0.2$ \\
$(\mathrm{dp} / \mathrm{dt})_{\max }$ & $\mathrm{bar} / \mathrm{s}$ & $399 \pm 28$ & $393 \pm 31$ & $387 \pm 33$ & $402 \pm 29$ & $396 \pm 33$ & $382 \pm 33$ \\
$\mathrm{~K}_{\mathrm{G}}$ & $\mathrm{bar} \cdot \mathrm{m} / \mathrm{s}$ & $108 \pm 8$ & $107 \pm 9$ & $105 \pm 9$ & $109 \pm 9$ & $107 \pm 9$ & $104 \pm 9$ \\
$\mathrm{LEL}^{1}$ & $\%$ & $3.5 \pm 0.2$ & $3.5 \pm 0.2$ & $3.0 \pm 0.2$ & $3.5 \pm 0.2$ & $3.0 \pm 0.2$ & $2.5 \pm 0.2$ \\
$\mathrm{UEL}^{2}$ & $\%$ & $13.0 \pm 0.2$ & $13.0 \pm 0.2$ & $13.5 \pm 0.2$ & $13.5 \pm 0.2$ & $13.5 \pm 0.2$ & $13.0 \pm 0.2$ \\
$\mathrm{t}_{\mathrm{ex}}$ & $\mathrm{ms}$ & $77 \pm 4$ & $75 \pm 4$ & $72 \pm 4$ & $166 \pm 8$ & $156 \pm 8$ & $142 \pm 8$ \\
\hline \multicolumn{7}{c}{${ }^{1}$ Lower explosion limit, ${ }^{2}$ Upper explosion limit. }
\end{tabular}

The presented explosion pressures averages for pure 2-propanol and 1-propanol/2-propanol-air mixtures reported for different temperatures differs considering the reproducibility given in [17] and are consistent with the data published in [8] for 1-propanol. The reported $(\mathrm{dp} / \mathrm{dt})_{\max }$ of 2-propanol is close to that reported for 1-propanol in [8]. The explosion characteristics dissimilarity could be attributed to the chain structure. As the chain length of the alcohols increases, thermal decomposition through $\mathrm{C}-\mathrm{C}$ bonds becomes more prevalent. Because $\mathrm{C}-\mathrm{C}$ bonds are weaker than the $\mathrm{C}-\mathrm{OH}$ bond, 1-propanol (unlike 2-propanol) does not lose the $\mathrm{OH}$ group in an initiation step [22]. However, because of the relative weakness of the $\mathrm{C}-\mathrm{OH}$ bond at a central part, 2-propanol loses its - $\mathrm{OH}$ group easily. This trend is similar in all initial conditions. The values of $t_{e x}$ presented are influenced by the volume and are comparable between 1-propanol and 2-propanol and only slightly differ for the 1-propanol/2-propanol-air mixture. Table 6 compares the data of maximum explosion pressure, maximum rate of pressure rise, and combustion time experimentally derived in this study with the values adopted from the literature.

Table 6. Presented and published $\mathrm{p}_{\max }$ and $\mathrm{K}_{\mathrm{G}}$ values.

\begin{tabular}{ccccccc}
\hline Chemical & p $_{\max }(\mathbf{b a r})$ & $\begin{array}{c}\mathbf{K}_{\mathbf{G}} \\
\mathbf{( b a r} \cdot \mathbf{m} / \mathbf{s})\end{array}$ & $\begin{array}{c}\text { Volume } \\
\mathbf{( \mathbf { m } ^ { 3 } )}\end{array}$ & $\begin{array}{c}\text { Temperature } \\
\left.\mathbf{(}{ }^{\circ} \mathbf{C}\right)\end{array}$ & $\begin{array}{c}\text { Equivalence } \\
\text { Ratio }\end{array}$ & Reference \\
\hline $\mathrm{CH}_{3} \mathrm{OH}$ & $7.1-8.2$ & $105-107$ & $0.005-0.020$ & $50-100$ & $1.00-1.26$ & {$[11,12]$} \\
$\mathrm{C}_{2} \mathrm{H}_{5} \mathrm{OH}$ & $7.9-8.7$ & $95-135$ & $0.005-0.020$ & $100-120$ & $1.00-1.10$ & {$[15,16]$} \\
$1-\mathrm{C}_{3} \mathrm{H}_{7} \mathrm{OH}$ & $7.7-8.7$ & $86-97$ & $0.020-1.000$ & $50-150$ & 1.06 & {$[8]$} \\
$2-\mathrm{C}_{3} \mathrm{H}_{7} \mathrm{OH}$ & $7.3-8.7$ & $89-98$ & $0.020-1.000$ & $50-150$ & 1.06 & Present \\
$1 \mathrm{P}+2 \mathrm{P} 1$ & $7.6-8.2$ & $105-108$ & $0.020-1.000$ & $50-150$ & 1.06 & Present \\
$1-\mathrm{C}_{4} \mathrm{H}_{9} \mathrm{OH}$ & $5.5-5.7$ & $95-100$ & $0.0053^{2}$ & 120 & 1.00 & {$[13]$} \\
$1-\mathrm{C}_{5} \mathrm{H}_{11} \mathrm{OH}$ & $5.6-5.7$ & $90-95$ & $0.0053^{2}$ & $120-160$ & 1.00 & {$[13,14]$} \\
\hline
\end{tabular}

${ }^{1} 1 \mathrm{P}+2 \mathrm{P}=1-\mathrm{C}_{3} \mathrm{H}_{7} \mathrm{OH}+2-\mathrm{C}_{3} \mathrm{H}_{7} \mathrm{OH}$ mixture for $\mathrm{f}=0.5 ;{ }^{2}$ lengths/diameter $=1.17$.

The values in Table 6 are close to the literature-derived values. The values of $\mathrm{p}_{\max } 1-\mathrm{C}_{4} \mathrm{H}_{9} \mathrm{OH}$ and $1-\mathrm{C}_{5} \mathrm{H}_{11} \mathrm{OH}$ differ from other published data. In Table 6, for example, the values of $p_{\max }$ for methanol adopted from [12] (7.1 bar and 8.2 bar) clearly appear to be quite different based on initial conditions (temperature, pressure, equivalence ratios). At the initial temperature, the value published by [14] was 5.6 bar, which is similar to value of 5.5 bar obtained by [13]. The (dp/dt) $\max$ of 1-propanol and 2-propanol show agreement with the values for ethanol, 1-butanol, and 1-pentanol measured in a $0.005 \mathrm{~m}^{3}$ cylinder. From Table 6 , it is obvious that the $(\mathrm{dp} / \mathrm{dt})_{\max }$ values are highly sensitive to the experimental conditions, mainly the vessel volume and shape used for their determination. The closer the volume of $\mathrm{V}=1.00 \mathrm{~m}^{3}$ to the standard explosion chamber, the smaller the deviation and the more accurate the application of the cubic law [23]. The measured values of deflagration index were $89-98 \mathrm{bar} \cdot \mathrm{m} / \mathrm{s}$ for 2-propanol and 105-108 bar-m/s for 1-propanol/2-propanol-air mixtures. Thus, in terms of reactivity, 2-propanol is characterized as less reactive than 1-propanol/2-propanol-air mixtures. As shown in Table 6, the values reported on deflagration index, $\mathrm{K}_{\mathrm{G}}$, of 2-propanol are in good agreement with the presented values for ethanol, 1-propanol, 1-butanol, and 1-pentanol but are lower than the published values for methanol. Meanwhile, the values of $\mathrm{K}_{\mathrm{G}}$ for 1-propanol/2-propanol-air 
mixtures are similar to the values of methanol. Considering these results, the oxidation and overall stoichiometry of the mixture seems to follows the dominant pathways as methanol in the given initial temperature ranges more than 1-propanol and 2-propanol. The described behavior needs more rigorous experimental investigation from the chemical point of view to elucidate the possible mechanisms of action behind the presented experiments. Table 7 summarizes the experimentally derived data for the explosion limits of alcohols reported in the literature. The maximum experimental uncertainty for LEL and UEL in Table 7 is $0.2 \%$ absolute.

Table 7. Presented and published explosion ranges (in vol.\%).

\begin{tabular}{ccccccccc}
\hline Chemical & $\begin{array}{c}\text { IFA }^{\mathbf{1}} \\
{[24]}\end{array}$ & $\begin{array}{c}\text { ILO }^{2} \\
\text { [25] }\end{array}$ & $\begin{array}{c}\text { Merck } \\
\text { [26] }\end{array}$ & $\begin{array}{c}\text { Penta } \\
\text { [27] }\end{array}$ & $\begin{array}{c}\text { SFPE }^{3} \\
\text { [28] }\end{array}$ & $\begin{array}{c}\text { DIPPR }^{4} \\
\text { [29] }\end{array}$ & $\begin{array}{c}\text { Yaws, C.L. } \\
\text { [30] }\end{array}$ & Present \\
\hline $\mathrm{CH}_{3} \mathrm{OH}$ & $6.0-50.0$ & $5.5-44.0$ & $5.5-44.0$ & $6.0-36.0$ & $6.7-36.5$ & $7.2-36.5$ & $6.0-36.0$ & \\
$\mathrm{C}_{2} \mathrm{H}_{5} \mathrm{OH}$ & $9.0-44.0$ & $3.3-19.0$ & $3.1-27.7$ & $3.5-15.0$ & $3.3-19.0$ & $3.3-19.0$ & $4.3-19.0$ & \\
$1-\mathrm{C}_{3} \mathrm{H}_{7} \mathrm{OH}$ & $2.1-19.9$ & $2.1-13.5$ & $2.1-19.2$ & $2.1-13.7$ & $2.2-13.5$ & $2.1-14.0$ & $2.0-12.0$ & \\
$2-\mathrm{C}_{3} \mathrm{H}_{7} \mathrm{OH}$ & $2.0-13.4$ & $2.0-12.7$ & $2.0-13.4$ & $2.0-12.7$ & $2.0-11.8$ & $2.0-12.7$ & $2.0-12.7$ & $2.0-14.0$ \\
$1 \mathrm{P}+2 \mathrm{P}^{5}$ & & & & & & & & $2.5-13.5$ \\
$1-\mathrm{C}_{4} \mathrm{H}_{9} \mathrm{OH}$ & $1.4-11.3$ & $1.4-11.3$ & $1.4-11.3$ & $1.4-11.3$ & $1.4-11.3$ & $1.7-11.3$ & $1.4-11.2$ & \\
$1-\mathrm{C}_{5} \mathrm{H}_{11} \mathrm{OH}$ & $1.3-10.5$ & $1.2-10.5$ & $1.6-8.0$ & $1.2-10.0$ & $1.2-10.0$ & $1.4-10.0$ & $1.2-10.0$ & \\
\hline
\end{tabular}

\footnotetext{
${ }^{1}$ Institut für Arbeitsschutz der Deutschen Gesetzlichen Unfallversicherung, Sankt Augustin, Germany, ${ }^{2}$ International Labour Organization, Geneva, Switzerland, ${ }^{3}$ Society of Fire Protection Engineers, Gaithersburg, USA, ${ }^{4}$ Design Institute for Physical Property Research, Fort Washington, USA, ${ }^{5} \mathrm{P}+2 \mathrm{P}=1-\mathrm{C}_{3} \mathrm{H}_{7} \mathrm{OH}+2-\mathrm{C}_{3} \mathrm{H}_{7} \mathrm{OH}$ mixture for $\mathrm{f}=0.5$.
}

The present experimentally derived explosion range of 2.0-14.0 vol.\% for 2-propanol corresponds well with the trend found in different data compilations provided by chemical databases, chemical company material safety data sheets, and the National Fire Protection Association. There are small differences between the presented higher explosion limit of 2-propanol and the published values due to an elevated initial temperature. Our experimental explosion range of $2.5-13.5$ vol.\% for the tested 1-propanol/2-propanol-air mixtures is close to the ILO and Penta-derived range of 2.1-13.5 and 2.1-13.7 vol.\% for 1-propanol. As compared with the experimental results, the lower explosion limit of the mixture is slightly higher than the explosion limit of 2-propanol and at the same time the higher explosion limit of the mixture is slightly lower than the explosion limit of both 2-propanol and 1-propanol. Such diversity is mainly due to the physicochemical properties of the mixed alcohols. The main limitation of this work is the more rigorous insightful chemical interpretation. It is lacking because the presented closed spherical methods do not allow straight and deeper experimental view into a chemical combustion problem. Such view could be given by the studies that involves experiments using for example a shock tube set-up, direct laser absorption using a mid-infrared QCL system, flow reactor pyrolysis, rapid compression machines, and premixed flat flame set-up. Even in these studies the mechanism of propanol isomers oxidation is not established to compare with methanol or ethanol. Nevertheless, there are still many safety aspects for the premixed flames of the alcohol-air mixtures needed to be clarified, such as analysis of heat release (or mass burning rate) and burning velocities (flame development duration and combustion duration) in which the presented data plays important role.

\section{Conclusions}

In this work, the experimental study of the explosion characteristics of propanol isomer-air mixtures at different equivalence ratios, volumes, and initial temperatures was performed. 2-propanol and 1-propanol/2-propanol with air mixtures have been characterized in the gas phase by $0.02 \mathrm{~m}^{3}$ and $1.00 \mathrm{~m}^{3}$ for the first time. The presented data allowed to compare the explosion characteristics of the monoalcohol-substituted compounds $\mathrm{C}_{n} \mathrm{H}_{2 n+1} \mathrm{OH}(\mathrm{n}=1-5)$ at elevated temperatures. An extensive set of explosion characteristics was obtained, allowing a systematic comparison of the explosion behavior properties to be made among the entire series. The main conclusions are summarized as follows: 
- The propanol-air mixtures gave the maximum explosion pressures and the highest deflagration index values at the equivalence ratio of 1.06 .

- Among propanol isomer-air mixtures, the maximum explosion pressure decreased in the order of 1-propanol-air, 2-propanol-air, and 1-propanol/2-propanol-air mixtures. The maximum explosion pressure decreased with increasing initial temperature and slightly decreased with increasing volume.

- The change of initial temperature only slightly influences the maximum rates of pressure rise and deflagration indexes (in both explosion vessel volumes). The maximum rate of pressure rise slightly decreased with an increasing initial temperature and slightly decreased with increasing volume.

- For 2-propanol-air mixture lower explosion limit values decreased with an increasing temperature from $3.5 \pm 0.2 \%$ to $3.0 \pm 0.2 \%$ for $0.02 \mathrm{~m}^{3}$ and from $2.5 \pm 0.2 \%$ to $2.0 \pm 0.2 \%$ for $1.00 \mathrm{~m}^{3}$. Upper explosion limit values increased with increasing temperature from $14.0 \pm 0.2 \%$ to $14.5 \pm 0.2 \%$ for $0.02 \mathrm{~m}^{3}$ and from $13.0 \pm 0.2 \%$ to $13.5 \pm 0.2 \%$ for $1.00 \mathrm{~m}^{3}$.

- For 1-propanol/2-propanol-air mixtures lower explosion limit values decreased with an increasing temperature from $3.5 \pm 0.2 \%$ to $3.0 \pm 0.2 \%$ for $0.02 \mathrm{~m}^{3}$ and from $3.5 \pm 0.2 \%$ to $2.5 \pm 0.2 \%$ for $1.00 \mathrm{~m}^{3}$. Upper explosion limit values increased with increasing temperature from $13.0 \pm 0.2 \%$ to $13.5 \pm 0.2 \%$ for $0.02 \mathrm{~m}^{3}$ and decreased with increasing temperature from $13.5 \pm 0.2 \%$ to $13.0 \pm 0.2 \%$ for $1.00 \mathrm{~m}^{3}$.

- The time to reach the maximum explosion pressure decreased with increasing initial temperature in the order of 1-propanol, 1-propanol + 2-propanol mixture, and 2-propanol. Moreover, it increased greatly with an increasing explosion vessel volume.

The most important results from evaluated experiments are in normalised maximum rates of pressure rise, $\mathrm{K}_{\mathrm{G}}$, 89-98 bar.m/s for 2-propanol and 105-108 bar.m/s for 1-propanol/2-propanol-air mixtures given by the combination of 0.20 and $1.00 \mathrm{~m}^{3}$ vessels at different temperatures regimes. These values are used to describe the effect of isomer blends on a deflagration process that is the paper's added value to the existing knowledge. The experiments carried out for this paper enable further studies for insightful chemical interpretation.

Author Contributions: Conceptualization, J.S. and T.O.; Data curation, J.S.; Methodology, J.S.; Supervision, T.O.; Visualization, J.S.; Writing—original draft, J.S.

Funding: This research was funded by the European regional development fund project "Increase of research capacity and quality of INEF center", grant number CZ.1.05/2.1.00/19.0407, and the APC was funded by "Research of conversion processes and utilization of waste heat in the framework of fuel-energy technological complexes", grant number SP 2019/89.

Conflicts of Interest: The authors declare no conflict of interest.

\section{References}

1. Chang, W.R.; Hwang, J.J.; Wu, W. Environmental impact and sustainability study on biofuels for transportation applications. Renew. Sustain. Energy Rev. 2017, 67, 277-288. [CrossRef]

2. Kumar, B.R.; Muthukkumar, T.; Krishnamoorthy, V.; Saravanan, S. A comparative evaluation and optimization of performance and emission characteristics of a DI diesel engine fueled with n-propanol/diesel, n-butanol/diesel and n-pentanol/diesel blends using response surface methodology. RSC Adv. 2016, 6, 61869-61890. [CrossRef]

3. Balogh, P.; Bai, A. Internet-orientated Hungarian car drivers' knowledge and attitudes towards biofuels. Renew. Sustain. Energy Rev. 2015, 48, 17-26. [CrossRef]

4. Saladini, F.; Patrizi, N.; Pulselli, F.N. Guidelines for emergy evaluation of first, second and third generation biofuels. Renew. Sustain. Energy Rev. 2016, 66, 221-227. [CrossRef]

5. Sarathy, S.M.; Oßwald, P.; Hansen, N.; Kohse-Höinghaus, K. Alcohol combustion chemistry. Prog. Energy Combust. Sci. 2014, 44, 40-102. [CrossRef]

6. Skřínský, J.; Dolníček, P.; Skřínská, M.; Marek, J.; Lukešová, P. Flashpoint prediction for binary mixtures of alcohols with water in order to improve their safety. Chem. Eng. Technol. 2015, 38, 727-733. [CrossRef] 
7. Skřínský, J.; Vereš, J.; Borovec, K. Experimental Modelling of Autoignition Temperature for Alkyl/Alkenyl Products from Fischer-Tropsch Synthesis. MATEC Web Conf. 2018, 168, 07014. [CrossRef]

8. Skřínský, J. Influence of Temperature and Vessel Volume on Explosion Characteristics of Propanol/Air Mixtures in Closed Spherical Vessels. Chem. Eng. Technol. 2018, 70, 1351-1355. [CrossRef]

9. Skřínská, M.; Skřínský, J.; Dolníček, P.; Lukešová, P.; Přichystalová, R.; Serafínová, C. BLEVE—Cases, Causes, Consequences and Prevention. Mater. Sci. Forum 2015, 811,91-94. [CrossRef]

10. Abbasi, T.; Abbasi, S.A. The boiling liquid expanding vapour explosion (BLEVE): Mechanism, consequence assessment, management. J. Hazard. Mater. 2007, 141, 489-519. [CrossRef] [PubMed]

11. Zhang, Z.; Huang, Z.; Wang, X.; Zheng, J.; Miao, H.; Wang, X. Combustion characteristics of methanol-Air and methanol-air-diluent premixed mixtures at elevated temperatures and pressures. Appl. Therm. Eng. 2009, 29, 2680-2688. [CrossRef]

12. Mitu, M.; Brandes, E. Explosion parameters of methanol-air mixtures. Fuel 2015, 158, 217-223. [CrossRef]

13. Li, Q.; Cheng, Y.; Huang, Z. Comparative assessment of the explosion characteristics of alcohol-air mixtures. J. Loss Prev. Proc. 2015, 37, 91-100. [CrossRef]

14. Li, Q.; Cheng, Y.; Jin, W.; Huang, Z. Comparative study on the explosion characteristics of pentanol isomer-air mixtures. Fuel 2015, 161, 78-86. [CrossRef]

15. Mitu, M.; Brandes, E. Influence of pressure, temperature and vessel volume on explosion characteristics of ethanol/air mixtures in closed spherical vessels. Fuel 2017, 203, 460-468. [CrossRef]

16. Mitu, M.; Brandes, E.; Hirsch, W. Mitigation effects on the explosion safety characteristic data of ethanol/air mixtures in closed vessel. Process Saf. Environ. Prot. 2018, 117, 190-199. [CrossRef]

17. EN 15967: Determination of Maximum Explosion Pressure and the Maximum Rate of Pressure Rise of Gases and Vapours; European Committee for Standardization: Brussels, Belgium, 2011.

18. EN 1839: Determination of the Explosion Limits and the Limiting Oxygen Concentration (LOC) for Flammable Gases and Vapours; European Committee for Standardization: Brussels, Belgium, 2017.

19. Chen, H.X.; Liu, N.A.; Shu, L.F.; Zong, R.W. Smoothing and differentiation of thermogravimetric data of biomass materials. J. Therm. Anal. Calorim. 2004, 78, 1025-1041. [CrossRef]

20. Seifert, E. OriginPro 9.1: Scientific Data Analysis and Graphing Software-Software Review. J. Chem. Inf. Model. 2014, 54, 1552. [CrossRef] [PubMed]

21. Hu, E.; Tian, H.; Zhang, X.; Li, X.; Huang, Z. Explosion characteristics of n-butanol/iso-octane-air mixtures. Fuel 2017, 188, 90-97. [CrossRef]

22. Glassman, I.; Yetter, R.A. Combustion, 4th ed.; Academic Press: Cambridge, MA, USA, 2008.

23. NFPA 68. Guide for Venting of Deflagrations, 1st ed.; National Fire Protection Association: Quincy, MA, USA, 2000.

24. IFA. GESTIS Substance Database-Information System on Hazardous Substances of the German Social Accident Insurances; Institut für Arbeitsschutz der Deutschen Gesetzlichen Unfallversicherung: Sankt Augustin, Germany, 2018.

25. ILO. International Safety Chemical Cards Database. Available online: http://www.ilo.org/dyn/icsc/showcard. home (accessed on 15 February 2019).

26. Merck Index, 14th ed.; Merck: Whitehouse Station, NJ, USA, 2007.

27. PENTA s.r.o. Material Safety Data Sheets; Penta: Prague, Czech Republic, 2017; Available online: https://www.pentachemicals.eu/en/ (accessed on 15 February 2019).

28. SFPE. Handbook of Fire Protection Engineering, 2nd ed.; Society of Fire Protection Engineers: Boston, MA, USA, 1995.

29. AIChE. DIPPR Project 801-Full Version; Design Institute for Physical Property Research/AIChE: Fort Washington, PA, USA, 2015.

30. Yaws, C.L. Chemical Properties Handbook: Physical, Thermodynamics, Environmental, Transport, Safety E Health Related Properties for Organic E Inorganic Chemicals, 1st ed.; McGraw-Hill: New York, NY, USA, 1999.

(C) 2019 by the authors. Licensee MDPI, Basel, Switzerland. This article is an open access article distributed under the terms and conditions of the Creative Commons Attribution (CC BY) license (http://creativecommons.org/licenses/by/4.0/). 